\title{
THE EFFECT OF END USER PERCEPTIONS OF INFORMATION TECHNOLOGIES ON THE INFORMATION SHARING
}

\author{
*Ibrahim PINAR \\ ** Özge MEHTAP \\ ***Esra ERZENGIN \\ * Istanbul University, Turkey \\ **Istanbul Bilgi University, Turkey \\ ***Beykent University, Turkey
}

\begin{abstract}
In recent decades, extant studies have focused on dominance of Information Technologies (IT) using different perspectives. While some of these studies utilized domains of IT management, remaining scholarly works dealt with issues of employee perceptions regarding IT usage and how IT usage affects employee outcomes such as job satisfaction. Accordingly, aim of this study is to explore and measure how IT related perceptions of employees determine the use and sharing of information they derive out of using the system effectively. We conceptualized the perceptions in terms of perceived ease of use, perceived usefulness, perceived self-efficacy and perceived information strenght loss. Employee satisfaction will be evaluated as a mediating variable between IT perceptions and information sharing resulting from these employee perceptions. We will test our model using a 114sample unit size of employees from 3 different universities. The obtained data are analyzed through SPSS. Relaibility, normality, factor and regression analysis was conducted in order to test the hypothesis. Whether we could not find any mediation effect of the satisfaction in the model; the results revealed that both the perceived usefulness and ease of use effect knowledge sharing through IT, however satisfaction is only effected by perceived usefulness.
\end{abstract}

Keywords: Information Technologies, Information Sharing, IT Perceptions, End User Perceptions, End User Satisfaction

\section{INTRODUCTION}

In todays business world, information is one of the most indispensable asset that provides competitive and strategic advantage. Information Technologies is a significant resource in collecting and utilizing information. The information is being collected, used and improved through this unbounded resource. However it is futile to have information technologies if people do not know and learn how to use it and if they are unwilling and unsatisfied toward those tools (Tippins and Sohi, 2003). Information Technologies are also called communication, telecommunication or information and communication Technologies. Through information technologies it is also provided to exchange the business information (ideas, questions or suggestions) among the employees, design the business flow and also socialization between the employees (Travica, 1988). There are various technologies and systems related to information management but one important point is that the users have to have the adequate motivation to use them (Kankanhalli et al., 2005). There are also many factors which effect the motivation of employees in positive or negative directions.

Researchers have been emphasizing the importance of information technologies infrastructure and applications on the information and knowledge integration. Some examples to the mostly used information technologies in today's business World are; shared databases, intranets, portals, some web-based network systems, electronic data management systems and knowledge management systems or the e-mail. The usage of those systems have been increasing the information sharing throughout the organizations. However there are some internal factors that effect the usage of those systems which also effect the information sharing system. The end user is the key factor here who actualize by implementing technologies. Henceforth the positive perceptions of end users toward the technology which is being used in the organization, may lead to their satisfaction with the system and also more effective usage of those systems. 


\section{End-User Perceptions Toward IT Usage}

There are a number of models and theories aimed at measuring end user reactions to Technologies. Some of them include, Technology Acceptance Model (TAM), Social Cognitive Theory (SCT) and Theory of Planned Behavior (TPB). The concepts which are going to be analyzed in the study are examined in the context of those theories.

\section{Perceived Usefulness and Ease of Use}

According to the Technology Acceptance Model, perceived usefulness and ease of use of the technology are the most substantial factors for the usage of those Technologies and also are the most important reasons behind the user's attitudes and behaviors (Fischer, 2005). Those two factors are also accepted as the determinant measures by the "Information Systems Success Models" (Kulkarni, 2006). By "perceived usefulness" it is meant that the the end user believes in the systems' performance escalating feature. If the users does not believe in the system's usefulness for themselves and the organization, the usage frequency and also information sharing will be automatically decreased for that reason.

Ease of use is also called the "user friendliness" of the system, in the technical language. The easy usage of the system means that, the data entry to the system and also to find the data in the system does not require too much effort or bother. The ease of use of the technologies also makes it easier for employees to accept the technology (Mahmood et al., 2000). While motivating the end user, the perceived ease of use also increases the perceived usefulness of the system. Henceforth, it is propounded that the perceived usefulness and ease of use will have a positive effect on the end user satisfaction (Lai, 2009). Due to the Planned Behavior Theory(PBT), computer usage is a function of people's behavioral inclinations. Individual attitudes are important in technology usage, in other words, technology usage is subjective. This theory in this way achieves to predict different persons' attitudes in different contexts. PBT also enhances perceived usefulness and ease of use as the basics of the behavior toward technology. According to that theory behavior is effected some unwritten rules which means norms (Kankanhalli et al., 2005).

\section{Self-Efficacy}

Self-efficacy concept is a cognitive factor that has been put in to the behavioral theory by Social Cognitive Theory or Model (Bandura, 1977). Social Cognitive Theory has been focused on the self efficacy in the performance. Self efficacy is the belief of one person to herself that she has the adequate ability and knowledge about so called business or situation. The person's achieved performance also has a certain amount of impact on the future self efficacy (Fischer, 2005). According to the Social Cognitive Theory people are not just motivated by environmental factor. Self efficacy perception is an internal factor. If a person believes that she/he is efficient in using computer makes her/him perceive that she achieved a job successfully (Compeau and Higgins, 1995). In their study on teachers, Yuen and Ma, have put forth that the knowledge, ability and attitudes teachers have on computers, are substantial factors in their acceptance of computer aided education (Yuen and Ma, 2004). The previous studies present that the computer self efficacy has positive effects on perceived usefulness and ease of use (Lai, 2009). For that reason, one of the most basic requirements of efficient computer usage is self efficacy.

\section{Satisfaction}

User satisfaction is defined as the pleasure that the users of information technologies get from the usage and the positive attitudes that the individuals have towards the information technologies. Satisfaction takes place as a mediator variable in various models and researches of information technologies usage. Satisfaction may be derived from the practicality of the system which means the ease of use and also from the advantages of the system's content. Since 1980s end user satisfaction is used as a significant factor and there are several models set in which satisfaction factors take part.

Delone and McLean identified the success of informatiom systems with user satisfaction (Delone and McLean, 1992). According to their model they assert that user satisfaction is derived from the quality of the system and information and this leads to individual and organizational effects. Wixon and Todd identified satisfaction with Technology Acceptance Model and they argued that the quality of the system and information leads to satisfaction and then this results in perceived usefulness and ease of use (Wixon and Todd, 2005). 


\section{Information Strength Loss}

Sometimes there can also be a perception of strength replacement in the use of information technologies tools and in this respect user perceptions and attitudes towards IT can change because knowledge also means possessed power. IT is a factor that has the capacity to change this power. Conversion of proprietary information into the information that is known by large masses through IT systems leads to redistribution of power and redistribution of power can cause resistance of various organizational cultures (Zack, 1999). The users become worried and insecure beause of the concerns regarding this issue, and for this reason users can have reluctant and unsure approach towards new technologies. Therefore information sharing depends on individual fear of strength loss. IT usage as well as the process of information sharing will be imperiled as long as the individuals perceive IT structures as innovations leading to strength loss (Lai, 2009).

\section{Knowledge Sharing Through IT}

Knowledge sharing is the voluntary transfer of information for the use of others (Davenport et al., 1998). Interpersonal knowledge sharing is an individual participation to the organizational collective knowledge and to this respect it is a contributory attitude towards organizational learning (Cabrera and Cabrera, 2002). According to Beckman, knowledge sharing is one of the most important factors that enhances organizational performance and agility (Beckman, 1997). Argote, Beckman and Epple (1990) and Baum and Ingram (1998) propound that organizations which have effective information distribution channels are more productive. Internet, world wide web and other developments on information technologies are the factors that accelerate information and knowledge flow. According to Nonaka, information is created and managed by individuals in organizations (Nonaka, 1994). IT is one of the most significant ways of transferring and protection of the knowledge created and managed by the individuals in cretaion of organizational memory (Kim and Lee, 2006). Cabrera and Cabrera (2002), commented on knowledge sharing as it is the individual contribution to organizational information. Knowledge sharing is seeking for information and providing information mutually. Bartol and Srivastava defined the ways of knowledge sharing as interactive and formal sharing between teams and business units, through informal interactions, in communities gathered together for a specific topic, and the transfer of knowledge to the organizational database (Bartol and Srivastava, 2002). Use of information technologies, particularly communication through e-mail, sharing ideas easily, unrestricted behaviors etc. lead to creation of new ideas and changes in ideas. This brings an increase in knowledge sharing and communication between departments (Janson et al., 2007).

\section{RESEARCH MODEL AND METHOD}

\section{The Model and The Hypothesis}

In this study, perceptions of IT users and effects of knowledge sharing through IT usage by the medation of satisfaction are analyzed.

Figure 1. Research Model

$$
\begin{array}{ll}
\text { User Perceptions in IT Use: } \\
\hline & \text { Perceived Usefulness } \\
\text { - } & \text { Ease of Use } \\
\text { - } & \text { Personal } \\
& \text { Competencies } \\
\text { - } & \text { Information Strength } \\
& \text { Loss }
\end{array}
$$

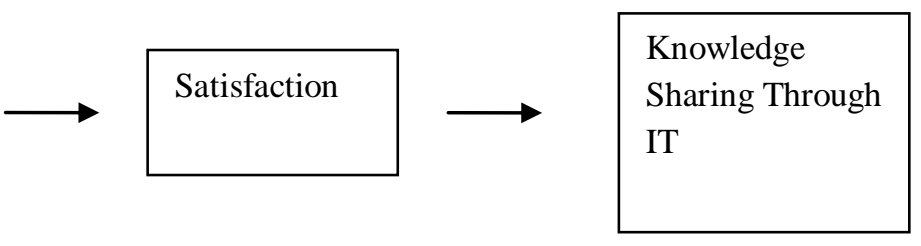

According to the research model, perceived usefulness, ease of use, personal competencies, and information strength loss effect users' satisfaction of those technologies which in turn effect knowledge sharing through IT usage. It is argued that these initial three dimensions have positive effect on satisfaction. Satisfaction of software increases when computer technology users in the organization believe in the usage advantages. In addition to the usage advantages, individuals perceived personal competencies on technology usage also claimed to have positive effects on the dependent and the mediator variable. Information strength loss factor is considered as a variable that 
Journal of Global Strategic Management | V. 6 | N. 1 | 2012-June | isma.info | 32-41 | DOI: 10.20460/JGSM.2012615784

has negative effects on the results. Individuals do not prefer to use IT tools if they perceive knowledge as a personal power and they perceive the accession to knowledge by the others as the information strength loss. Perceiving the use of IT tools as information strength loss may cause dissatisfaction of the use of these tools. According to the model, increase in satisfaction lead by user perceptions will cause knowledge sharing through information technologies.

Accordingly, th hypotheses are as below;

Hypothesis 1: High perceived usefulness increases knowledge sharing through IT.

Hypothesis 2: High perceived ease of use increases knowledge sharing through IT.

Hypothesis 3: High perceived self efficacy increases knowledge sharing through IT.

Hypothesis 4: High perceived information strength loss decreases knowledge sharing through IT.

Hypothesis 5: Satisfaction increases the positive effect of perceived usefulness on knowledge sharing through IT.

Hypothesis 6: Satisfaction increases the positive effect of ease of use on knowledge sharing through IT.

Hypothesis 7: Satisfaction increases the positive effect of self efficacy on knowledge sharing through IT.

Hypothesis 8: Increase in information strength loss decreases knowledge sharing through IT due to diminishing satisfaction.

\section{Method and Scales}

In the research, survey method is used as the data gathering technique, 114 respondents from 3 different universities were reached with the convenience sampling method. The common characteristic of the respondents, who answered the questionnaire composed of 23 propositions, is that, all of them use an information technology tool in the institutions they are working. The questionnaire is prepared by using five point Likert scale that represents the propositions between 'strongly agree' and 'strongly disagree'. Perceived usefulness is obtained from the scale generated by Lai (2009) composed of 4 questions. In order to measure 'ease of use', the scale of Goodman and Darr (1998) which is composed of 4 questions is used. Self efficacy is measured using the scale of Kalman (1999) including 4 questions. The information strength loss is measured using the scales generated by Kankanhalli et al. (2005), Thibaut and Kelley (1986) and Orlikowski (1993). Knowledge sharing is meaured by the scale of Kankanhalli generated from Wasko and Faraj (2000). And finally, the scale of Lai (2009) is taken as basis for satisfaction.

\section{RESEARCH RESULTS}

\section{Analysis of Validity and Reliability}

In the research, factor analysis is used in order to test structural validity. Each factor's reliability is tested following the exploratory factor analysis. As a result of the factor analysis, all the variables are gathered under a single dimension as indicated in the literature, only self efficacy variable is separated into two dimensions. The first subdimension consists of three variables and the fourth variable is divided into a separate dimension. Since the explanation of one dimension with only one proposition is not accepted statistically, the proposition is removed from the questionnaire and the factor analysis is reconducted.

The results of the factor analysis are mentioned as in Table 1. Field (2000) argues that the lower limit should be 0.5 for KMO and the data set can not be divided into factors for KMO $<0.50$.

Barlett test is a chi-square test and offers a statistical standard for the data to be modelled with factor analytic model. In the research the KMO values are over 0.500 and Barlett test is statistically significant on 0.000 point for every variable. 
Journal of Global Strategic Management | V. 6 | N. 1 | 2012-June | isma.info | 32-41 | DOI: 10.20460/JGSM.2012615784

Table 1. The Results of the Factor Analysis (Bartlett's Value: .000)

\begin{tabular}{|c|c|c|c|c|}
\hline Factor Name & Related Questions & $\begin{array}{l}\text { Factor } \\
\text { Value }\end{array}$ & \begin{tabular}{|l|} 
Total \\
Descriptio \\
n Value \\
$\%$
\end{tabular} & $\begin{array}{l}\text { KMO } \\
\text { Value }\end{array}$ \\
\hline \multirow{3}{*}{ Satisfaction } & The system we are using satisfies me & .918 & \multirow{3}{*}{85.298} & \multirow{3}{*}{.758} \\
\hline & I love the system we are using & .931 & & \\
\hline & In general the system is successfull & .921 & & \\
\hline \multirow{4}{*}{$\begin{array}{l}\text { Perceived } \\
\text { Usefulness }\end{array}$} & IT we are using increases my occupational performance & .930 & \multirow{4}{*}{86.881} & \multirow{4}{*}{.816} \\
\hline & IT we are using increases my occupational effectiveness & .961 & & \\
\hline & IT we are using increases my efficieny & .948 & & \\
\hline & I think IT we are using is useful for my job & .887 & & \\
\hline \multirow{4}{*}{ Sharing } & $\begin{array}{l}\text { I get pleasure of sharing my knowledge with other } \\
\text { employees }\end{array}$ & 894 & \multirow{4}{*}{90.045} & \multirow{4}{*}{.811} \\
\hline & I get pleasure of helping others by sharing through IT & .951 & & \\
\hline & I feel good when I help the others by sharing through IT & .974 & & \\
\hline & I enjoy sharing with the others through IT & .974 & & \\
\hline \multirow{4}{*}{$\begin{array}{l}\text { Knowledge } \\
\text { Power }\end{array}$} & $\begin{array}{l}\text { Sharing my knowledge through IT causes my knowledge, } \\
\text { which makes me to attract attention among others, to be loss }\end{array}$ & 892 & \multirow{4}{*}{84.822} & \multirow{4}{*}{.761} \\
\hline & $\begin{array}{l}\text { Sharing my knowledge through IT causes my knowledge, } \\
\text { that no one has, to be loss }\end{array}$ & .933 & & \\
\hline & $\begin{array}{l}\text { Sharing my knowledge through IT leads me to loose the } \\
\text { power base }\end{array}$ & .936 & & \\
\hline & $\begin{array}{l}\text { Sharing my knowledge through IT causes the value which } \\
\text { only I possess }\end{array}$ & .922 & & \\
\hline \multirow{4}{*}{ Ease of Use } & $\begin{array}{l}\text { Too much effort should be exerted in order to find } \\
\text { knowledge in the system we are using }\end{array}$ & .886 & \multirow{4}{*}{77.500} & \multirow{4}{*}{.731} \\
\hline & $\begin{array}{l}\text { Too much time is needed in order to find knowledge in the } \\
\text { system we are using }\end{array}$ & .936 & & \\
\hline & To find knowledge is easy in the system we are using & .731 & & \\
\hline & $\begin{array}{l}\text { I can not find knowledge available in the system we are } \\
\text { using }\end{array}$ & .951 & & \\
\hline \multirow{3}{*}{ Self Efficacy } & $\begin{array}{l}\text { I can use a new IT system even if I have not used a similar } \\
\text { one before }\end{array}$ & .722 & \multirow{3}{*}{78.991} & \multirow{3}{*}{.608} \\
\hline & $\begin{array}{l}\text { I can use a new IT system only if there is a guideline that I } \\
\text { can base on }\end{array}$ & .962 & & \\
\hline & $\begin{array}{l}\text { I can use a new IT system only if there is a guidance tool in } \\
\text { it }\end{array}$ & .961 & & \\
\hline
\end{tabular}

As it is shown in Table 2 table reliability statistics are also above 0.80 which means all the meaures are highly reliable. 
Table 2. Reliability Analysis Results

\begin{tabular}{|l|l|}
\hline Variables & $\begin{array}{l}\text { Cronbach Alpha } \\
\text { Values }\end{array}$ \\
\hline Perceived Usefulness & 0.949 \\
\hline Perceived Ease of Use & 0.900 \\
\hline Self-Efficacy & 0.860 \\
\hline Information Strength Loss & 0.940 \\
\hline Satisfaction & 0.913 \\
\hline Knowledge Sharing Through IT & 0.961 \\
\hline
\end{tabular}

\section{Regression Analysis}

In the first stage of the regression analysis, the effects of perceived usefulness, ease of use, loss of knowledge power and self-efficacy on knowledge sharing through IT is measured. The results can be seen on Table 3. It can be seen that corrected $\mathrm{R}^{2}$ is .232 and model is significant as a whole according to the result of Anova $(\mathrm{p}=.000)$ when the influence of all the perceptions on knowledge sharing through IT are analysed. Therefore it can be said that independent variables have an effect on dependent variable as a whole to a certain extent. However, it can be seen that this influence is derived from perceived usefulness when the beta coefficients of the independent variables are examined individually. It can be understood that the coefficient of perceived usefulness is far above the other variables and only perceived usefulness has a statistically significant effect on the dependent variable. $(\mathrm{p}=.000)$

\section{Table 3. Regression Results of Knowledge Sharing Through IT}

\begin{tabular}{|l|l|l|l|l|}
\hline Variables & $\boldsymbol{\beta}$ & Anl. (p) & Anova & \multirow{2}{*}{$\Delta \mathbf{R}^{\mathbf{2}}$} \\
\hline Perceived Usefulness & .443 & .000 & & \\
\cline { 1 - 3 } Perceived Ease of Use & -.140 & .051 & \multirow{2}{*}{.000} & \multirow{2}{*}{.232} \\
\cline { 1 - 3 } Perceived Self Efficacy & .003 & .974 & & \\
\cline { 1 - 3 } Perceived Information Strength Loss & .076 & .365 & & \\
\hline
\end{tabular}

The regression results are displayed in Table 4 which are applied in order to measure the effect of the satisfaction variable, used as the mediating variable, on the dependent variable. Accordingly, it can be seen that satisfaction has a statistically significant effect on knowledge sharing.

\section{Table 4. The Effect of Satisfaction on Knowledge Sharing Through IT}

\begin{tabular}{|l|l|l|l|l|}
\hline Variable & $\beta$ & Anl. (p) & Anova & $\Delta \mathrm{R}^{2}$ \\
\hline Satisfaction & .252 & .001 & .000 & .079 \\
\hline
\end{tabular}

The model is significant as a whole according to the analysis of the effects of independent variables on satisfaction which is asserted as the mediating variable and the corrected $\mathrm{R}^{2}$ value is .458 . This means that independent variables have an influence on satisfaction variable as a whole. However, it can be seen that in this model perceived loss of information and perceived self-efficacy do not have statistically significant influence on satisfaction and only perceived usefulness and ease of use have influence on satisfaction when the beta coefficients and significancy values are analysed. 
Journal of Global Strategic Management | V. 6 | N. 1 | 2012-June | isma.info | 32-41 | DOI: 10.20460/JGSM.2012615784

Table 5. The Effect of Independent Variables on Satisfaction

\begin{tabular}{|l|l|l|l|l|}
\hline Variables & $\boldsymbol{\beta}$ & Anl. (p) & Anova & \multirow{2}{*}{$\Delta \mathbf{R}^{\mathbf{2}}$} \\
\cline { 1 - 3 } Perceived Usefulness & .631 & .000 & & \\
\cline { 1 - 3 } Perceived Ease of Use & .174 & .014 & \multirow{2}{*}{.000} & \multirow{2}{*}{.458} \\
\cline { 1 - 3 } Perceived Self Efficacy & -.128 & .136 & & \\
\cline { 1 - 3 } Perceived Information Strength Loss & .054 & .513 & & \\
\hline
\end{tabular}

Perceived usefulness and ease of use have effects on satisfaction to a certain extent, only perceived usefulness variable is analyzed in hierarchical regression analysis in which the effect of the meadiating variable is measured because only perceived usefulness variable has significant effect on knowledge sharing through IT. Table 6 displays the results of the analysis. According to these results, even if the model is significant as a whole (Anova $\mathrm{p}=.000$ ), satisfaction, that has an effect on knowledge sharing, does not have statistically significant $(\mathrm{p}=.696)$ effect when it is analysed together with perceived usefulness. While perceived usefulness has an effect on knowledge sharing through IT $\left(\mathrm{R}^{2}=.233\right)$.

Table 6. Regression Analysis For Knowledge Sharing through IT

\begin{tabular}{|l|l|l|l|l|l|}
\hline Variables & $\mathrm{R}^{2}$ Change & $\beta$ & F Change & Anova & Corrected $\mathrm{R}^{2}$ \\
\hline 1.Perceived Usefulness & .233 & .446 & .000 & .000 & .220 \\
\cline { 1 - 4 } 2.Satisfaction & .001 & -.037 & .696 & & \\
\hline
\end{tabular}

In the light of the results of this research, it is not possible to measure the mediating variable effect between satisfaction and perceived usefulness and ease of use and knowledge sharing. The model which is set according to the analysis is as below. Perceived usefulness has an effect both on satisfaction and knowledge sharing through IT. However satisfaction does not have a mediating role between other two variables. Perceived ease of use only has an effect on satisfaction. So we can say that just hypothesis 1 is accepted and all the other hypothesis are rejected.

Figure 2. Final Research Model

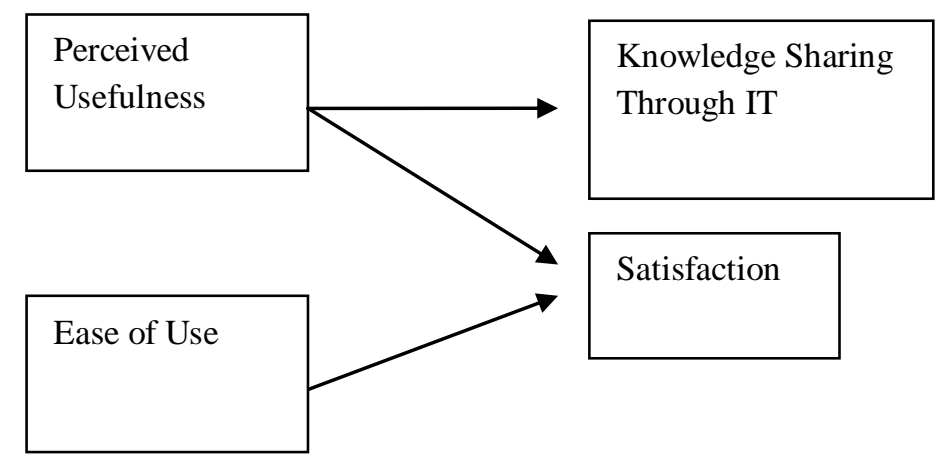

\section{DISCUSSION AND RESULTS}

It is certain that there may be so many factors that may effect knowledge sharing through IT. However, this study is limited with the effects of employee perceptions on this process, for users' acceptance of the technologies', is one of the basic requirements for advanced technologies to be used efficiently in enterprises. This acceptance may depend on different perceptions. Users refuse to use or do not use these tools efficiently when they have negative perceptions for IT. This may cause intraorganizational disruptions for knowledge sharing.

According to previous researches, there is a relation between perceived usefulness, ease of use and satisfaction. This study also supports this relation but it is determined that the effect of perceived usefulness has a great effect on satisfaction than the effect of ease of use. Satisfaction has an effect on 
knowledge sharing to a certain extent, when satisfaction is analyzed together with perceived usefulness this effect becomes statistically unsignificant. The model indicates that only perceived usefulness has a significant effect on knowledge sharing through IT.

In light of the results of this study it can be said that managers should take user perceptions into consideration. The user friendliness of the system is a very crucial point while implementing Information Technologies in the organization. End users should also be educated in terms of information technology tools and executives and information technology departments should provide guidance and assitance for the users in order to provide knowledge sharing through IT.

In this study the effects of self efficacy and information stregth loss on the dependent variable are not indicated, but the effect of the perceptions on technology tools usage is obvious. Therefore, this research provides a guidance for the related studies and gives opinions for further researches. 


\section{REFERENCES}

Argote, L. Beckman S.L. and Apple D. (1990), The Persistence and Transfer of. Learning in Industrial Settings, Management Science, 36(2), pp.140-154.

Bandura, A. (1977), Self-efficacy: Toward a unifying theory of behavioral change, Psychological Review, 84, pp.191-215.

Bartol, K. and Srivastava, A. (2002), Encouraging knowledge sharing: The role of organisational rewards, Journal of Leadership and Organisation Studies, 9(1), pp. 64-76.

Baum, J. A. C. and Ingram, P. (1998), Survival-enhancing learning in the Manhattan hotel industry, 1898-1980, Management Science, 44(7), pp.996-1016.

Beckman, Jill N. (1997), Positional faithfulness, positional neutralization and Shona vowel harmony, Phonology, 14, pp.1-46.

Cabrera Á. and Cabrera E.F. (2002), Knowledge-sharing Dilemmas Organization Studies, 23, pp. 687710

Compeau, D.R., and Higgins, C.A. (1995), Computer Self-Efficacy: Development of a Measure and Initial Test, MIS Quarterly, 19(2), pp.189-211.

Davenport, T.H., De Long, D.W. and Beers, M. C. (1998), Successful knowledge management projects, Sloan Management Review, 39(2), pp.43-57.

DeLone, W.H. and McLean, E.R, (1992), Information Systems Success: The Quest for the Dependent Variable, Information Systems Research, 3 (1), pp. 60-95.

Field, A. (2000), Discovering Statistics Using SPSS for Windows, London: Sage.

Fischer, G. (2005), Beyond Binary Choices: Understanding and Exploiting Trade-Offs to Enhance Creativity, In J. S. Gero, \& M. L. Maher (Eds.), Computational and Cognitive Models of Creative Design, Key Centre of Design Computing and Cognition, University of Sydney, Sydney, Australia, pp.71-92, http://13d.cs.colorado.edu/ gerhard/papers/final-heron05-final.pdf

Goodman, P.S. and Darr, E.D. (1998), Computer-aided Systems and Communities as Mechanisms for Organizational Learning, MIS Quarterly, 22(4), pp.417-440.

Janson, Marius and Dubravka Cecez (2007), Prospering in a Transition Economy Through Information Technology-Supported Organizational Learning, Information Systems Journal, 17(1), s. 3-36.

Kalman, M. E. (1999), The effects of organizational commitment and expected outcomes on the motivation to share discretionary information in a collaborative database: communication dilemmas and other serious games, unpublished Ph.D. Dissertation, University of Southern California.

Kankanhalli, Atreyi, Bernard C.Y. Tan and Kwok-Kee Wei, (2005), Contributing Knowledge to Electronic Knowledge Repositories: An Empirical Investigation, MIS Quarterly, 29(1) pp.113-143.

Kim, S., and Lee, H. (2006), The impact of organizational context and information technology on employee knowledge-sharing capabilities, Public Administration Review, 66(3), pp.370-385.

Kulkarni UR, Ravindran S, (2006), A Knowledge Management Success Model: Theoretical Development and Empirical Validation, Journal of Management Information Systems, 23(3), pp.309347.

Lai, Jung-Yu (2009), How Reward , Computer Self-Efficacy , and Perceived Power Security Affect Knowledge Management Systems Success : An Empirical Investigation in High-Tech Companies, Journal of the American Society for Information Science, 60(2), pp. 332-347.

Mahmood, Mo Adam, Janice M. Burn, Leopoldo A. Gemoets, Carmen Jacquez, (2000), Variables Effecting İnformation Technology End-User Satisfaction: A Meta-Analysis Of The Empirical Literature, International Journal of Human-Computer Studies, 52, pp.751-771.

Nonaka, I. (1994), A dynamic theory of organizational knowledge creation, Organization Science, 5 (1), pp.14-37. 
Orlikowski, W. J. (1993), Case tools as organizational change: investigating incremental and radical changes in systems development, MIS Quarterly, 17(3), pp.309-340.

Thibaut, J. W. and Kelley, H. H. (1986), The Social Psychology of Groups. New York: Wiley.

Tippins, Michael J. and Ravipreet S. Sohi, (2003), It competency and firm performance: Is organizational learning a missing link?, Strategic Management Journal, 24, pp.745-761.

Travica, Bob, (1998), Information Aspects of New Organizational Designs: Exploring the NonTraditional Organization, Journal Of The American Society For Information Science, 49(13), pp.1224-1244.

Wasko, M.; Faraj, S. (2000), It is what one does: why people participate and help others in electronic communities of practice, Journal of Strategic Information Systems, 9 (2-3), pp.155-173.

Wixon, B.H. and Todd, P.A. (2005), A Theoretical Integration of User Satisfaction and Technology Acceptance, Information Systems Research, 16(1), pp. 85-102.

Yuen, Allan H.K., Will W.K. Ma, (2004), Knowledge sharing and teacher acceptance of web based learning system, Ascilite, 2004 Proceeding Content.

http://www.ascilite.org.au/conferences/perth04/procs/yuen.html

Zack M.H. (1999), Developing a Knowledge Strategy, California Management Review, 41(3), pp.125-145. 